FRACTURE MECHANICS CRITERIA AND APPLICATIONS 
ENGINEERING APPLICATION OF FRACTURE MECHANICS

Editor-in-Chief: George C. Sih

VOLUME 10

The titles published in this series are listed at the end of this volume. 


\title{
Fracture Mechanics Criteria and Applications
}

\author{
E.E. GDOUTOS
}

Division of Engineering Mechanics

Department of Civil Engineering

Democritus University of Thrace, Xanthi, Greece 


\section{Library of Congress Cataloging-in-Publication Data}

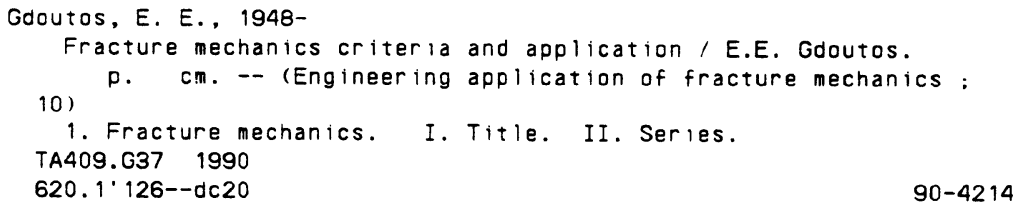

Published by Kluwer Academic Publishers, P.O. Box 17, 3300 AA Dordrecht, The Netherlands

Kluwer Academic Publishers incorporates the publishing programmes of D. Reidel, Martinus Nijhoff, Dr W. Junk, and MTP Press.

Sold and distributed in the U.S.A. and Canada

by Kluwer Academic Publishers,

101 Philip Drive, Norwell, MA 02061, U.S.A.

In all other countries, sold and distributed by Kluwer Academic Publishers Group, P.O. Box 322, 3300 AH Dordrecht, The Netherlands

printed on acid free paper

\section{All Rights Reserved}

(C) 1990 Kluwer Academic Publishers

Softcover reprint of the hardcover 1st edition 1990

No part of the material protected by this copyright notice may be reproduced or utilized in any form or by any means, electronic or mechanical, including photocopying, recording or by any information storage and retrieval system, without written permission from the copyright owner. 


\section{Contents}

Editor's Preface $\quad$ ix

Preface

1. Introductory chapter 1

1.1. Conventional failure criteria 1

1.2. Characteristic brittle failures 3

1.3. Griffith's work 5

1.4. Fracture mechanics $\quad 10$

$\begin{array}{ll}\text { References } & 13\end{array}$

2. Linear elastic stress field in cracked bodies

$\begin{array}{lr}\text { 2.1. Introduction } & 15\end{array}$

2.2. Crack deformation modes and basic concepts 16

2.3. Eigenfunction expansion method for a semi-infinite crack 18

2.4. Westergaard method 23

2.5. Singular stress and displacement fields 29

2.6. Method of complex potentials 36

2.7. Numerical methods $\quad 41$

2.8. Experimental methods $\quad 55$

$\begin{array}{ll}\text { 2.9. Three-dimensional crack problems } & 61\end{array}$

2.10. Cracks in bending plates and shells 66

$\begin{array}{ll}\text { References } & 71\end{array}$

3. Elastic-plastic stress field in cracked bodies 76

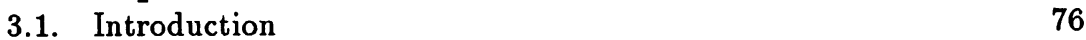

3.2. Approximate determination of the crack-tip plastic zone $\quad 78$

3.3. Small-scale yielding solution for antiplane mode 84

$\begin{array}{ll}\text { 3.4. Complete solution for antiplane mode } & 92\end{array}$

3.5. Irwin's model $\quad 93$

3.6. Dugdale's model 96

3.7. Singular solution for a work-hardening material 100 
$\begin{array}{ll}\text { 3.8. Numerical solutions } & 105\end{array}$

$\begin{array}{lr}\text { References } & 109\end{array}$

4. Crack growth based on energy balance 112

$\begin{array}{lr}\text { 4.1. Introduction } & 112\end{array}$

4.2. Energy balance during crack growth 113

$\begin{array}{ll}\text { 4.3. Griffith theory } & 116\end{array}$

4.4. Graphical representation of the energy balance equation 122

4.5. Equivalence between strain energy release rate and stress intensity factor $\quad 127$

$\begin{array}{lr}\text { 4.6. Compliance } & 129\end{array}$

4.7. Critical stress intensity factor fracture criterion 132

4.8. Experimental determination of $K_{\mathrm{I} c} \quad 137$

4.9. Crack stability 142

4.10. Crack growth resistance curve ( $R$-curve) method 147

$\begin{array}{ll}\text { 4.11. Mixed-mode crack propagation } & 154\end{array}$

$\begin{array}{lr}\text { References } & 159\end{array}$

5. J-Integral and crack opening displacement fracture criteria 162

$\begin{array}{ll}\text { 5.1. Introduction } & 162\end{array}$

5.2. Path-independent integrals 163

$\begin{array}{ll}\text { 5.3. J-integral } & 164\end{array}$

5.4. Relationship between the $J$-integral and potential energy 168

$\begin{array}{ll}\text { 5.5. } J \text {-integral fracture criterion } & 170\end{array}$

5.6. Experimental determination of the $J$-integral 173

5.7. Stable crack growth studied by the $J$-integral 180

5.8. Mixed-mode crack growth 183

5.9. Crack opening displacement (COD) fracture criterion 185

$\begin{array}{ll}\text { References } & 191\end{array}$

6. Strain energy density failure criterion 195

$\begin{array}{ll}\text { 6.1. Introduction } & 195\end{array}$

6.2. Volume strain energy density 197

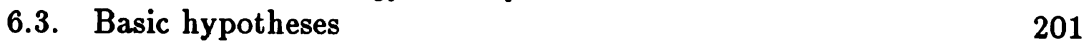

6.4. Two-dimensional linear elastic crack problems 203

6.5. Uniaxial extension of an inclined crack 205

6.6. Three-dimensional linear elastic crack problems 212

6.7. Bending of cracked plates 216

$\begin{array}{ll}\text { 6.8. Ductile fracture } & 219\end{array}$

6.9. Failure initiation in bodies without pre-existing cracks 223

6.10. Other criteria based on energy density 225

$\begin{array}{ll}\text { References } & 226\end{array}$

7. Dynamic fracture $\quad 230$

$\begin{array}{ll}\text { 7.1. Introduction } & 230\end{array}$

$\begin{array}{ll}\text { 7.2. Mott's model } & 231\end{array}$ 
7.3. Stress field around a rapidly propagating crack 234

$\begin{array}{ll}\text { 7.4. Strain energy release rate } & 239\end{array}$

7.5. Transient response of cracks to impact loads 241

7.6. Standing plane waves interacting with a crack 244

$\begin{array}{ll}\text { 7.7. Crack branching } & 247\end{array}$

$\begin{array}{ll}\text { 7.8. Crack arrest } & 249\end{array}$

7.9. Experimental determination of crack velocity and dynamic stress intensity factor $\quad 250$

$\begin{array}{ll}\text { References } & 252\end{array}$

8. Fatigue and environment-assisted fracture 255

$\begin{array}{ll}\text { 8.1. Introduction } & 255\end{array}$

8.2. Fatigue crack propagation laws 257

$\begin{array}{ll}\text { 8.3. Fatigue life calculations } & 261\end{array}$

8.4. Variable amplitude loading 262

8.5. Mixed-mode fatigue crack propagation 265

8.6. Nonlinear fatigue analysis based on the strain energy
density theory

8.7. Environment-assisted fracture $\quad 272$

$\begin{array}{lr}\text { References } & 275\end{array}$

9. Engineering applications $\quad 278$

$\begin{array}{ll}\text { 9.1. Introduction } & 278\end{array}$

9.2. Fracture mechanics design philosophy 279

$\begin{array}{ll}\text { 9.3. Design example problems } & 281\end{array}$

9.4. Fiber-reinforced composites 290

9.5. Concrete 295

9.6. Crack detection methods 301

$\begin{array}{ll}\text { References } & 303\end{array}$

$\begin{array}{ll}\text { Author Index } & 307\end{array}$

$\begin{array}{ll}\text { Subject Index } & 311\end{array}$ 


\section{Editor's preface}

It is difficult to do justice to fracture mechanics in a textbook, for the subject encompasses so many disciplines. A general survey of the field would serve no purpose other than give a collection of references. The present book by Professor E. E. Gdoutos is refreshing because it does not fall into the esoteric tradition of outlining equations and results. Basic ideas and underlying principles are clearly explained as to how they are used in application. The presentations are concise and each topic can be understood by advanced undergraduates in material science and continuum mechanics. The book is highly recommended not only as a text in fracture mechanics but also as a reference to those interested in the general aspecis of failure analysis.

In addition to providing an in-depth review of the analytical methods for evaluating the fundamental quantities used in linear elastic fracture mechanics, various criteria are discussed reflecting their limitations and applications. Particular emphases are given to predicting crack initiation, subcritical growth and the onset of rapid fracture from a single criterion. Those models in which it is assumed that the crack extends from tip to tip rely on the specific surface energy concept. The differences in the global and energy states before and after crack extension were associated with the energy required to create a unit area of crack surface. Applications were limited by the requirement of self-similar crack growth. Quantities such as energy release rate, stress intensity factor, path independent integral, etc. fall into this category. An alternative view based on physical observation is that crack growth is not continuous but is a discrete process of failure initiation, repeated many times, at a finite distance from the crack tip. Attention would then be focused on the energy stored in a unit volume of material reaching a critical state. Crack growth is considered as the loci of fracture initiation sites. Consistency can thus be achieved not only in assessing initiation, slow growth and rapid fracture but also in the simultaneous description of yielding and fracture. Macroplasticity off to the side of a macrocrack extension is distinguished from the microplasticity that may prevail ahead of a growing macrocrack. By the same token, microcracks may occur in regions of macroplasticity. The time and location at which energy is dissipated to deform and fracture at a specified size scale of material need to be identified. The book 
gives a comprehensive explanation of how the stationary values of the strain energy density function can be applied to locate the sites of yield and fracture initiation. Yielding and fracture at the macroscopic level are shown to occur at different locations. The former always precedes the latter. Many illustrative examples are presented and critiqued against the other criteria. Fatigue crack growth can be treated in the same way by considering the cumulation of the strain on volume energy density. When the disturbance becomes time dependent, inertia effects of material elements around the crack come into play. This can occur regardless of whether the crack is stationary or moving. Further material on dynamic fracture can be found in the references.

The important contribution on applying fracture mechanics principles is not the number of examples but the methodology for resolving the loading rate and specimen size effect. Straight line relations obtained from the constant rate change of strain energy density factor with crack growth permit linear interpolation of the results. Data on crack growth can thus be obtained with a limited number of experiments and can be used to predict situations other than those tested. A realistic application of fracture mechanics could not be made without a sound understanding of the fundamentals. To this end, the book has met the objective. 


\section{Preface}

The objective of engineering design is the determination of the geometry and dimensions of machine or structural elements and the selection of material in such a way that the elements perform their operating function in an efficient, safe and economic manner. For this reason the results of stress and displacement analysis are coupled with an appropriate failure criterion, which is basically a postulate predicting the event of failure itself. Traditional failure criteria cannot adequately explain the number of structural failures that occur at stress levels considerably lower than the ultimate strength of the material. Example problems include bridges, tanks, pipes, weapons, ships, railways and aerospace structures. On the other hand, experiments performed by Griffith in 1921 on glass fibers led to the conclusion that the strength of real materials is much smaller, typically by two orders of magnitude, than their theoretical strength. In an effort to explain these phenomena the discipline of fracture mechanics has been created. It is based on the realistic assumption that all materials contain crack-like defects which constitute the nuclei of failure initiation.

Defects can appear in a structure in three major different ways: first, they can exist in a material due to its composition, as second-phase particles, debonds in composites, etc.; second, they can be introduced into a structure during fabrication, as in welds; and, third, they can be created during the service life of a component, like fatigue, environment-assisted or creep cracks. Fracture mechanics studies the load-bearing capacity of structures in the presence of initial defects, where a dominant crack is usually assumed to exist.

A new design philosophy is therefore introduced by fracture mechanics as opposed to the use of the conventional failure criteria. As catastrophic fracture is a consequence of the unstable propagation of a crack from a pre-existing defect, we are faced with the question: 'Can fracture be prevented by constructing structures that have no defects?' The answer is 'no', on the grounds of practicality. Then, the safe design of structures should proceed along two lines: either the safe operating load should be determined when a crack of a prescribed size is assumed to exist in the structure; or, given the operating load, the size of the crack that is created in the structure should be determined.

Fracture mechanics is searching for parameters which characterize the propen- 
sity of a crack to extend. Such a parameter should be able to relate laboratory test results to structural performance, so that the response of a structure with cracks can be predicted from laboratory test data. This is determined as a function of material behavior, crack size, structural geometry and loading conditions. On the other hand, the critical value of this parameter - known as fracture toughness, a property of the material - is determined from laboratory tests. Fracture toughness expresses the ability of the material to resist fracture in the presence of cracks. By equating this parameter to its critical value a relation is obtained between applied load, crack and structure geometry which gives the necessary information for structural design. Fracture toughness is used to rank a material's ability to resist fracture within the framework of fracture mechanics, in the same way that yield or ultimate strength is used to rank a material's resistance to yield or fracture in the conventional design criteria. In selecting materials for structural applications a choice has to be made between materials with a high yield strength but comparatively low fracture toughness or a lower yield strength but higher fracture toughness.

The phenomenon of fracture of a solid is complicated and depends on a wide variety of factors, including the macroscopic effects, the microscopic phenomena which take place at the locations where the fracture nucleates or grows, and the composition of the material. The study of the fracture process depends on the scale level at which it is considered. At one extreme is the rupture of cohesive bonds in the solid, and the associated phenomena take place within distances of the order of $10^{-7} \mathrm{~cm}$. For such studies the principles of quantum mechanics should be used. At the other extreme the material is considered as a homogeneous continuum and the phenomenon of fracture is studied within the framework of continuum mechanics and classical thermodynamics. Fracture studies that take place at scale levels between these two extremes concern movement of dislocations, formation of subgrain boundary precipitates and slip bands, grain inclusions and voids. Thus, the understanding of the phenomenon of fracture depends to a large extent on the successful integration of continuum mechanics with materials science, metallurgy, physics and chemistry. Due to the insurmountable difficulties encountered in an interdisciplinary approach the phenomenon of fracture is usually studied within only one of the three scale levels: namely, the atomic, the microscopic and the continuum. Attempts are under way to find a unified, interdisciplinary approach to the phenomenon of the failure of solids.

The purpose of this book is to present a clear, straightforward and unified interpretation of the basic problems of fracture mechanics with particular emphasis given to fracture mechanics criteria and their application in engineering design. The book is divided into nine chapters.

The first, introductory, chapter gives a brief account of some characteristic failures that could not be explained by the traditional failure criteria, and of Griffith's experiments which gave impetus to the development of a new philosophy in engineering design based on the discipline of fracture mechanics. The next two chapters deal with the determination of the stress and deformation fields in cracked bodies and provide the necessary prerequisite for the develop- 
ment of the criteria of fracture mechanics. More specifically, Chapter 2 covers the basic analytical, numerical and experimental methods for determining the linear elastic stress field in cracked bodies, with particular emphasis on the local behavior around the crack tip, and Chapter 3 is devoted to the determination of the elastic-plastic stress and displacement distribution around cracks for timeindependent plasticity. Addressed in the fourth chapter is the theory of crack growth, based on the global energy balance of the entire system. The fifth chapter deals with the theoretical foundation of the path-independent $J$-integral and its use as a fracture criterion. Furthermore, a brief presentation of the crack opening displacement fracture criterion is given. Chapter 6 studies the underlying principles of the strain energy density theory and demonstrates its usefulness and versatility in solving a host of two- and three-dimensional problems of mixedmode crack growth in brittle and ductile fracture. Chapter 7 presents in a concise form the basic concepts and the salient points of dynamic fracture mechanics. Addressed in Chapter $\mathbf{8}$ is the phenomenon of fatigue and environment-assisted crack growth which takes place within the framework of the macroscopic scale level. Finally, Chapter 9 presents the basic principles of engineering design based on the discipline of fracture mechanics and gives a number of example problems. The applicability of fracture mechanics to composites and concrete is also discussed. The chapter concludes with a brief description of the more widely used nondestructive testing methods for defect detection.

Particular care was taken throughout the book to give a clear, consistent, simple and straightforward presentation of the basic concepts of the discipline of fracture mechanics from a continuum mechanics viewpoint. The book is selfcontained and can be used as a textbook in undergraduate and postgraduate courses and as a reference book by all those who are interested in developing design methodologies and promoting research to include the influence of initial defects or cracks.

The author wishes to express his gratitude to Professor G. C. Sih of Lehigh University for his pioneering work on fracture mechanics on which parts of the book were based, his very stimulating discussions and his comments and suggestions during the writing of the book. Thanks are also due to my secretary, Mrs L. Adamidou, for typing the manuscript. Finally, I wish to express my gratitude to my wife, Maria, not only for proofreading the manuscript, but for her understanding and patience during the writing of the book. 